\title{
EL CONTROL DE CONVENCIONALIDAD Y LOS DERECHOS SOCIALES: NUEVOS DESAFÍOS EN ESPAÑA Y EN EL ÁMBITO COMPARADO EUROPEO (FRANCIA, ITALIA Y PORTUGAL)
}

\section{Control of conventionality and social rights: New challenges in Spain within the field of European Comparative Law (France, Italy and Portugal)}

\author{
LUIS JIMENA QUESADA ${ }^{1}$ \\ Universidad de Valencia \\ luis.jimena@uv.es
}

Cómo citar/Citation

Jimena Quesada, L. (2018).

El control de convencionalidad y los derechos sociales: nuevos desafíos en España y en el ámbito comparado europeo (Francia, Italia y Portugal).

Anuario Iberoamericano de Justicia Constitucional, 22, 31 -58.

doi: https://doi.org/10.18042/cepc/aijc.22.02

\section{Resumen}

El presente trabajo aborda el impacto positivo del control de convencionalidad como exigencia constitucional de coherencia normativa e institucional y de optimización de la dignidad humana a través de la protección de los derechos sociales. En efecto, con un enfoque de constitucionalismo multinivel, se toman en consideración los parámetros europeos en materia de derechos sociales (del Consejo de Europa

1 Catedrático de Derecho Constitucional, Universidad de Valencia. Expresidente del Comité Europeo de Derechos Sociales (Consejo de Europa). 
- especialmente, la jurisprudencia del Comité Europeo de Derechos Sociales - y de la Unión Europea) y la experiencia comparada en la cultura constitucional latinoeuropea (España, Francia, Italia y Portugal). El autor concluye poniendo el énfasis en el papel esencial de los órganos judiciales nacionales para articular correctamente los sistemas de fuentes jurídicas, de instituciones y de derechos fundamentales. Ahora bien, ese papel debe venir precedido y completado constantemente por una contribución sincera y positiva de la academia tendente a reforzar los estándares de los derechos sociales.

\section{Palabras clave}

Diálogo judicial; constitucionalismo multinivel; prevalencia de tratados; efectividad de derechos sociales.

\section{Abstract}

This essay tackles the positive impact of the control of conventionality as a constitutional requirement of coherence (at both normative and institutional levels) and optimization (of human dignity) through the protection of social rights. Indeed, under a multi-level constitutionalism approach, the European parameters in the field of social rights (those pertaining to the Council of Europe-especially the case-law of the European Committee of Social Rights - and those relating to the European Union) as well as the comparative experience in the Latin-European constitutional culture (Spain, France, Italy and Portugal) are taken into account. The author concludes by emphasizing the essential role of domestic courts in correctly articulating the systems of legal sources, institutions and fundamental rights. However, this role must be preceded and constantly completed by a sincere and positive contribution from Academia, aiming at strengthening social rights standards.

\section{Keywords}

Judicial dialogue; multi-level constitutionalism; prevalence of treaties; effectiveness of social rights. 


\section{SUMARIO}

I. CONSIDERACIONES INTRODUCTORIAS: EL CONTROL DE CONVENCIONALIDAD COMO EXIGENCIA CONSTITUCIONAL DE COHERENCIA NORMATIVA E INSTITUCIONAL Y DE OPTIMIZACIÓN PROTECTORA PARA LA DIGNIDAD. II. CONTROL DE CONVENCIONALIDAD Y DERECHOS SOCIALES EN ESPAÑA: 1. La inaplazable superación de los recelos dogmáticos al control de convencionalidad. 2. La positiva experiencia reciente y pujante de la jurisdicción ordinaria en materia de derechos sociales. III. CONTROL DE CONVENCIONALIDAD Y DERECHOS SOCIALES EN PERSPECTIVA COMPARADA LATINOEUROPEA: 1. La prácticamente consolidada experiencia francesa. 2. El peso entrecruzado del parámetro comunitario europeo en Italia. 3. La influencia condicionante del control de constitucionalidad en Portugal. IV. REFLEXIONES FINALES: LA INCOMPRENSIBLE DESAFECCIÓN ACADEMICISTA Y LA POSITIVA VOLUNTAD JURISDICCIONAL EN EL EJERCICIO DEL CONTROL DE CONVENCIONALIDAD Y EL RESPETO DE LA DIGNIDAD. BIBLIOGRAFIA.

\section{CONSIDERACIONES INTRODUCTORIAS: EL CONTROL DE CONVENCIONALIDAD COMO EXIGENCIA CONSTITUCIONAL DE COHERENCIA NORMATIVA E INSTITUCIONAL Y DE OPTIMIZACIÓN PROTECTORA PARA LA DIGNIDAD}

De entrada, soy consciente de que plantearse actualmente la posibilidad del control de convencionalidad en un Estado social y democrático de derecho e internacionalmente integrado se revela más controvertido que cuestionar en nuestros días la propia existencia de una jurisdicción y un control de constitucionalidad (esgrimiendo la insostenible soberanía parlamentaria), o que poner en entredicho el papel primordial de la jurisdicción ordinaria como defensora cotidiana de los derechos fundamentales (bajo el pretexto de configurarla irrealistamente como boca muda que pronunciaría las palabras de la ley).

En efecto, un orden constitucional contemporáneo no puede prescindir ni de una alta jurisdicción que asegure extraordinariamente la supremacía de la carta constitucional (ello sin perjuicio de la panoplia de competencias que en tal cometido se atribuya a dicha jurisdicción constitucional) ni de 
unos órganos jurisdiccionales que garanticen ordinariamente la eficacia de los derechos constitucionales, pues, en otro caso, el propio texto constitucional deviene papel mojado. Del mismo modo, entiendo que la prevalencia de las normas internacionales sobre las nacionales y el lógico control de convencionalidad susceptible de ser operado por los órganos jurisdiccionales domésticos deberían resultar constitucionalmente incontestables, más allá del modo - más o menos explícito - en que cada orden constitucional nacional haya interiorizado la solución de la Convención de Viena sobre el Derecho de los Tratados de 1969.

En realidad, esa prevalencia de las normas internas de producción internacional (señaladamente cuando, como en el caso que nos ocupa, reconozcan derechos humanos y sean más favorables que las de producción nacional) y el correspondiente control de convencionalidad, concebidos en clave de constitucionalización de la Convención de Viena de 1969, comportan simple y llanamente una exigencia constitucional de respeto de los compromisos internacionales. De tal suerte, canon de constitucionalidad y estándar internacional se perfilan como convergentes y complementarios.

Con semejantes premisas, deberían quedar superadas las antiguas disputas entre las normas internacionales y nacionales a cuenta de la discusión en torno al monismo, al dualismo o a la combinación de ambos (Cançado Trindade, 1995: 7 y 20), para sostener con firmeza y solidez que los diversos cánones normativos del sistema global de derechos humanos quedan articulados en aras de su optimización e «integralidad maximizadora» (Bidart Campos, 1994: 29-31). De hecho, la referencia aislada al control de convencionalidad en algunos sistemas constitucionales europeos (así lo es en los cuatro lationoeuropeos analizados en el presente ensayo, salvo en Francia) no lo es tal en el contexto latinoamericano (Bazán, 2010; Sagüés, 2011). En este, más allá de esas posturas encontradas entre monismo y dualismo, gana fuerza el juego combinado del binomio constitucionalidad-convencionalidad (Hitters, 2009) a través del planteamiento del valor supralegal —y aun supraconstitucional en algunos ordenamientos jurídicos- (Rouvillois, 2002: 327; Bidart Campos, 1996: 46) de los tratados internacionales (Riofrío Martínez-Villalba, 2007: 259).

Al tiempo, deben quedar zanjados los recelos entre derecho constitucional y derecho internacional, para avanzar por la senda de las sinergias siguiendo el movimiento de internacionalización del derecho constitucional y de constitucionalización del derecho internacional; de igual manera, especialmente en la órbita globalizada de los derechos humanos, es inexorable la internacionalización de otras disciplinas como el derecho penal, el derecho procesal, el derecho laboral, etc. 
Otra acotación. Cuando nos situamos en la esfera del derecho internacional de los derechos humanos (en este caso, de los derechos sociales), la eventual divergencia entre el canon doméstico y el estándar de producción externa no se producirá normalmente en el plano normativo, dado que las normas internacionales suelen contener cláusulas generales que devienen instrumentos vivos (adaptados a la realidad y enfocados al respeto de la dignidad humana y a la consecución de la justicia social) a través de la interpretación dinámica o evolutiva de las correspondientes instancias internacionales de control, monitoreo o garantía. En otros términos, la prevalencia del parámetro exterior vendrá dada por la asunción interna del texto y la interpretación internacionales, lo cual no debe sino entenderse como un acto de prevalencia de la misma fuerza normativa de la Constitución nacional, vigorizada a través de su apertura internacional.

En resumen, la puesta en práctica del control de convencionalidad ha de concebirse como una exigencia constitucional que, avalada por una adecuada praxis, permite fortalecer el conjunto de las fuentes del derecho dotándole de coherencia sistemática, engrasar el entramado institucional restándole fricciones interorgánicas $y$, ante todo, reforzar el sistema de derechos fundamentales imprimiéndole dinamismo y mejorando los medios de garantía, en este caso la garantía suministrada por la jurisdicción ordinaria. Naturalmente, la puesta en marcha de un mecanismo difuso de supervisión como es el control de convencionalidad pasa, irremediablemente, por el previo conocimiento de las normas y las jurisprudencias internacionales que sirven como parámetro de control y por el consecuente self-restraint en el momento de su efectivo ejercicio por la jurisdicción nacional (Gelli, 2007: 1-2).

Bajo el ángulo expuesto, las razonables cautelas con las que tiene que ser enfocado el control de convencionalidad (para evitar un activismo judicial que genere inseguridad jurídica y desigualdad aplicativa del derecho) no pueden erigirse en otros tantos pretextos para descartar ese control (para no dejar de infundir una necesaria voluntad jurisdiccional que, como se viene insistiendo, respondería a un mandato constitucional de optimización de los derechos y libertades). Las ventajas, en todo caso, parecen mayores que los inconvenientes; adicionalmente, aquellas serían trasunto de una obligación constitucional, mientras que estos traducirían excesivos recelos hacia un control difuso operado por la jurisdicción nacional.

Obviamente, la tarea formativa de la Judicatura y demás actores jurídicos no debe descuidarse. De todas formas, es menester recordar que, en el ámbito europeo, se asumió con naturalidad, y aun con ostensible entusiasmo, que la jurisdicción nacional estaba habilitada en el ámbito de la Unión Europea para operar semejante control difuso a través de los principios de primacía y efecto directo del derecho comunitario europeo. Luego, ¿por qué no admitir 
el ejercicio responsable del control de convencionalidad como elemento, no de debilidad, sino de fortaleza del ordenamiento constitucional?

\section{CONTROL DE CONVENCIONALIDAD Y DERECHOS SOCIALES EN ESPAÑA}

\section{LA INAPLAZABLE SUPERACIÓN DE LOS RECELOS DOGMÁTICOS AL CONTROL DE CONVENCIONALIDAD}

Como adelantaba, en mi opinión el ordenamiento español ofrece bases constitucionales explícitas que dan soporte al control de convencionalidad y a la efectividad de la tutela multinivel de los derechos, especialmente el mandato aplicativo de los tratados internacionales (arts. 93 a 96 de la Constitución española) en conjunción con el mandato interpretativo (del art. 10.2 de la propia Constitución) (Fernández de Casadevante y Jiménez García, 2006: 21 y 31; Sáiz Arnáiz, 1999; Aparicio Pérez, 1989; De Carreras Serra, 2000). En este sentido, del art. 96.1 de la Constitución española se deriva la superioridad de los tratados con respecto a la ley española y, en todo caso, ese carácter supralegal se revela indiscutible cuando se trata de tratados sobre derechos humanos (art. 94.1.c de la Carta Magna), por más que el texto constitucional español no hable explícitamente de esa supralegalidad (Peces Barba Martínez, 1988: 97).

Es cierto que en esto último diverge la Carta constitucional española de otras constituciones extranjeras, como es el caso de la francesa vigente de 1958 (art. 55)2 ${ }^{2}$. No obstante, el texto final del art. 96 de la Constitución de 1978 recoge esa superioridad aplicativa de los tratados sobre las leyes, en la línea de la Convención de Viena sobre el Derecho de los Tratados de 1969 (Carcassonne, 2002: 250). Con tal filosofía, sobre no ser necesario, la Ley 25/2014, de 27 de noviembre, de Tratados y otros Acuerdos Internacionales, viene a poner negro sobre blanco lo que dispone el reiterado art. 96 de la Constitución española al establecer explícitamente esa prevalencia (Jiménez García, 2015: 54).

Como antes se apuntaba, la lógica del principio de primacía del derecho de la Unión Europea es la misma que inspira el ejercicio del control de convencionalidad con apoyo en la posición prevalente o supralegal de los tratados internacionales. Si se tiene en mente ese sencillo paralelismo, quedarán

2 Según el art. 55 de la Constitución francesa, «los tratados o acuerdos regularmente ratificados o aprobados tienen, desde su publicación, una autoridad superior a la de las leyes, bajo reserva, para cada acuerdo o tratado, de su aplicación por la otra Parte». 
superados los recelos dogmáticos (acusadamente, en la doctrina constitucionalista) a la asunción del control de convencionalidad operado por los órganos jurisdiccionales. Cabalmente, aunque la primacía sea una creación jurisprudencial del Tribunal de Justicia de Luxemburgo en cuanto a su formulación (Tajadura Tejada y De Miguel Bárcena, 2008; Torres del Moral, 2010: 718724), ella no es ajena a la posición de los tratados comunitarios europeos en el ordenamiento interno a tenor de la Convención de Viena sobre el Derecho de los Tratados.

De análogo razonamiento se hizo eco, con gran acierto e inspirándose en la experiencia constitucional francesa, el Consejo de Estado español en su Memoria anual de 1997. Decía así el Consejo de Estado:

En las consultas sobre proyectos legislativos el Consejo de Estado sustituye su tradicional examen de legalidad del texto reglamentario por un doble control o examen de constitucionalidad y de "convencionalidad». Estas verificaciones se realizan también en materia reglamentaria, pero en materia legislativa se hace con mayor meticulosidad. También en los aspectos formales y de contenido se observan matices en los Dictámenes, posiblemente por el mayor rigor y mejor cuidado con que se emiten las consultas legislativas ${ }^{3}$.

\section{Y proseguía:}

Al examinar los anteproyectos legislativos, el Consejo de Estado realiza además lo que se ha venido llamando "control de convencionalidad». Es enteramente aplicable aquí la conclusión a la que ha llegado la doctrina francesa respecto a su Conseil d'État: desde que es consultado de un anteproyecto de ley, el Consejo de Estado debe sistemáticamente plantearse la cuestión de saber si ese proyecto es compatible con el Derecho Comunitario y el Derecho Internacional ${ }^{4}$.

Pero, sobre todo, al hilo del citado ejemplo, recuerda el Consejo de Estado el carácter supralegal o prevalente de los tratados internacionales, en estos términos: «La problemática de las relaciones entre la ley interna y los tratados internacionales correspondientes y la prevalencia de la fuente internacional, es objeto de examen detenido en el Dictamen 176/1997. [...] El Dictamen 4810/1997 advierte sobre la innecesidad de las cláusulas de reserva o remisión expresas a tratados por su dudosa utilidad, dada la primacía de éstos» (ibidem: 164-165.). Y agrega: «En esta materia el Consejo de Estado se mueve con un mayor margen creativo, que en la materia constitucional, dado lo limitado de

3 Memoria anual del año 2007, p. 149.

4 Memoria anual del año 1997, p. 158. 
la intervención del Tribunal Constitucional en materia de Tratados internacionales (artículo 95 de la Constitución española) y su rechazo a controlar el respeto de los compromisos internacionales y del Derecho comunitario».

Estimo que las citas anteriores quedan plenamente justificadas. Si se aplica esa lógica argumentativa al terreno de la técnica legislativa (fase de elaboración de la norma), ¿qué impide trasladarla al campo de la praxis judicial (fase de aplicación de la norma)? A mi entender, los argumentos tendentes a excluir el neto control difuso de convencionalidad de la esfera judicial ordinaria para reconducirla a la supervisión concentrada de la jurisdicción constitucional (Bandrés Sánchez-Cruzat, 1996: 134-136; Canosa Usera, 2015; Jimena Quesada, 2013) parecen poco realistas y, sobre todo, se alejan del principal papel y mayor virtud del primer control, a saber, la efectividad de la tutela judicial de los derechos fundamentales en plazo razonable. Efectivamente, al margen de ese obstáculo principal consistente en diferir el control a sede jurisdiccional constitucional con la consiguiente demora, se presenta irrealista esa solución por implicar incluso un cambio de mentalidad que, hoy por hoy, no se atisba todavía en la justicia constitucional española: esta ha rechazado incluir los tratados como parte del bloque de constitucionalidad al tiempo que de facto los ha utilizado aleatoriamente como tal parámetro.

Curiosamente, ha asumido el instituto francés del bloque de constitucionalidad con esa poca fortuna y aleatoriedad y, al tiempo, se ha mostrado reacio a reconocer explícitamente que la justicia ordinaria está habilitada para ejercer el control de convencionalidad. Dicho sea de paso, es mi parecer que tampoco hace falta que el Tribunal Constitucional efectúe ese reconocimiento, que ya se desprende de la propia Constitución. Ahora bien, lo que sucede es que el aval del Alto Tribunal serviría ciertamente para apuntalar la convicción y la voluntad positiva de los órganos jurisdiccionales ordinarios. Por el contrario, a día de hoy, no se vislumbra ese aval, hasta tal punto que podría argüirse que la Corte Constitucional española, en materia de control de convencionalidad, ni hace ni deja hacer, como en el seno del propio Tribunal se ha criticado.

Así, gran interés despierta el voto particular concurrente de Juan Antonio Xiol Rios (al que se adhieren Adela Asua Batarrita y Fernando Valdés DalRé) formulado a la Sentencia del Tribunal Constitucional núm. 270/2015, de 17 de diciembre, en donde se afirma que la cuestión del control de convencionalidad «debería ser sometida a una reconsideración más profunda por este Tribunal para evitar determinadas situaciones paradójicas que se plantean en el ordenamiento jurídico español» y con respecto a lo cual «este Tribunal, como máximo intérprete de la Constitución, deberá pronunciarse más fundadamente en algún momento». Y se recapitula así la crítica a esa elusión del control de convencionalidad: 
La actual jurisprudencia parece que aboca a que sólo se posibilite el desarrollo de ese control de convencionalidad de manera concreta por parte de los órganos judiciales cuando deba aplicarse la ley que se estime contraria a un tratado internacional a partir de considerarlo una mera cuestión de selección normativa, lo que, en su caso, podría ser impugnado en amparo por la vía del artículo 24.1 de la Constitución española en caso de arbitrariedad o irrazonabilidad. Ahora bien, no deja de resultar paradójico que en el contexto de una creciente propensión al control abstracto de normas con fundamento en razones de seguridad jurídica, el único control abstracto que quede ayuno de cualquier vía de planteamiento sea el control de convencionalidad de las normas con rango de ley que, si no puede ser ejercido por la jurisdicción ordinaria, tampoco este Tribunal está posibilitando que se ejerza a través del recurso de inconstitucionalidad o la cuestión de inconstitucionalidad por la vía de la invocación de los artículos 9.1 o 96 de la Constitución española.

Por lo demás, los recelos dogmáticos (y jurisdiccionales) se presentan tanto más injustificados cuanto que, en la praxis (y el cómputo no puede ser estadísticamente más sencillo, por su carácter excepcional), el ejercicio responsable del control de convencionalidad se operará en supuestos aislados en los que la norma internacional (y, sobre todo, la jurisprudencia internacional correspondiente) ofrezcan claridad y certeza en cuanto al supuesto controvertido, como queda ilustrado a continuación en el terreno de los derechos sociales.

\section{LA POSITIVA EXPERIENCIA RECIENTE Y PUJANTE DE LA JURISDICCIÓN ORDINARIA EN MATERIA DE DERECHOS SOCIALES}

La actual y prometedora praxis de la jurisdicción ordinaria española en el terreno de los derechos sociales se ha visto dinamizada por la asunción del parámetro de la Carta Social Europea del Consejo de Europa y la jurisprudencia de su instancia máxima de garantía —el Comité Europeo de Derechos Sociales- (Bonet Pérez, 2016a: 22; Bonet Pérez, 2016b: 122-127) en el contexto de la crisis económica y por referencia a dos ámbitos controvertidos, a saber, flexibilidad en el mercado laboral y flexiseguridad en el sistema de pensiones a cuenta de diversas decisiones adoptadas por dicho órgano frente a Grecia.

Con relación al primer ámbito, el Comité Europeo de Derechos Sociales dictó en el año 2012 las dos primeras decisiones que abordaron frontalmente la problemática de las medidas «anticrisis» de austeridad y flexibilidad del mercado laboral adoptadas bajo imposición de la Troika (Comisión Europea, Banco Central Europeo y Fondo Monetario Internacional). Se trata de las dos decisiones de fondo del Comité de 23 de mayo de 2012 de resolución de las reclamaciones colectivas n. ${ }^{\circ}$ 65/2011 y n. ${ }^{\circ}$ 66/2011 (ambas contra Grecia, formuladas por los sindicatos griegos Federación General de Empleados 
de las Compañías Públicas de Electricidad y Confederación de Sindicatos de Funcionarios Públicos).

En la primera decisión (Reclamación n. ${ }^{\circ}$ 65/2011), el Comité Europeo concluyó que se había producido una violación del art. 4.4 de la Carta Social, por cuanto la ley nacional que autorizaba el despido sin preaviso ni indemnización a los asalariados con contrato de duración indefinida durante un período inicial de doce meses es incompatible con dicha disposición de la Carta. En la segunda decisión (Reclamación n. ${ }^{\circ}$ 66/2011), el Comité llegó a la conclusión de violación de diversas disposiciones de la Carta Social (arts. $4.4,7.7,10.2$ y 12.3), al enjuiciar las disposiciones restrictivas sobre vacaciones anuales, sistemas de aprendizaje y formación, y cobertura de la seguridad social en los llamados "contratos de aprendizaje especiales» para asalariados de entre 15 a 18 años, así como las disposiciones referentes a la irrisoria remuneración (un pequeño porcentaje del salario mínimo nacional) susceptible de ser percibida por los asalariados recién incorporados al mercado laboral menores de 25 años.

Lo interesante de ambas decisiones es que el Comité Europeo ha establecido una especie de ponderación de las medidas de flexibilización con la salvaguardia prioritaria de la dignidad de los trabajadores y trabajadoras ${ }^{5}$.

5 En síntesis, el Comité sostuvo en su argumentación jurídica: «La crisis económica no debe traducirse en una reducción de la protección de los derechos reconocidos por la Carta. Los Gobiernos deben por tanto adoptar todas las medidas necesarias para conseguir que esos derechos sean efectivamente garantizados en el momento en el que la necesidad de protección se hace sentir más [...] si la crisis puede legítimamente conducir, en unos u otros ámbitos, a reorganizar los dispositivos normativos y las prácticas vigentes con vista a limitar algunos costes para los presupuestos públicos o a aligerar las cargas que pesan sobre las empresas, semejante reorganización no debería traducirse en una precarización excesiva de los beneficiarios de los derechos reconocidos por la Carta.

El Comité considera que una mayor flexibilidad en el trabajo para luchar contra el desempleo no puede conducir a privar a amplias categorías de asalariados, singularmente quienes ya no son titulares desde hace mucho tiempo de empleos estables, de sus derechos fundamentales en materia laboral, contra la arbitrariedad del empleador o los avatares de la coyuntura. Es precisamente a la instauración y al mantenimiento de tales derechos, en los dos ámbitos mencionados, a lo que tienden justamente las disposiciones de la Carta. Renunciar a tales garantías tendría, a mayor abundamiento, no solamente como efecto el hacer recaer sobre los asalariados indebidamente una parte excesiva de las consecuencias de la crisis, sino incluso aceptar efectos pro-cíclicos susceptibles de agravar la crisis y de aumentar la carga de los regímenes sociales, en particular los asistenciales, a menos que ello no suponga compensar las pérdidas de 
Ambas decisiones (lo mismo que las cinco decisiones de 7 de diciembre de 2012 sobre la drástica reducción de pensiones en Grecia, infra) han gozado de cierta aplicación por parte de los órganos jurisdiccionales nacionales y gran eco mediático, en la medida en que el Gobierno griego incidía en el argumento de haber adoptado dichas medidas por imposición de la Troika. Lo cual suscita las posibles divergencias de enfoques entre el Consejo de Europa y la Unión Europea (Jimena Quesada, 2016).

¿Qué ha sucedido en España? El Tribunal Constitucional se vio enfrentado de lleno a ese tipo de medidas anticrisis con motivo del recurso de inconstitucionalidad n. ${ }^{\circ}$ 5603-2012 interpuesto por el Parlamento de Navarra contra diversos preceptos de la Ley 3/2012, de 6 de julio, de medidas urgentes para la reforma laboral, resuelto en sentido desestimatorio mediante la Sentencia núm. 119/2014, de 16 de julio. En el recurso se denunciaba que, más allá de la pretendida superación de la rigidez del mercado laboral (con la nueva modalidad de "contrato de trabajo por tiempo indefinido de apoyo a los emprendedores» — análogo al examinado por el Comité Europeo en relación con Grecia-) y la flexibilización de la regulación de las instituciones laborales (nueva regulación del descuelgue o inaplicación en la empresa de los convenios colectivos aplicables, así como un arbitraje obligatorio), la reforma resultaría «más incisiva y de mayor envergadura, hasta el punto de que en algunos aspectos constituiría una ruptura con el modelo constitucional de relaciones laborales» (antecedente 2).

La Sentencia del Tribunal Constitucional núm. 119/2014 cuenta con un contundente voto particular discrepante suscrito por varios magistrados constitucionales que sí se hacen eco de la normativa y la jurisprudencia internacionales. Lo preocupante es que el Tribunal ha establecido un canon constitucional divergente con respecto al estándar europeo más favorable (Salcedo Beltrán, 2016b: 57-62; Santiago Rivera, 2016: 309-364; Valdés Dal-Ré, 2016b: 63-65). Y dicha brecha no debería producirse, por la sencilla razón de que, como se indicaba, el canon europeo es también canon constitucional (impuesto por los arts. 10.2 y 93 a 96 de la Constitución) y, consecuentemente, canon que se impone a la propia Corte Constitucional (Molina Navarrete, 2014: 183-190).

En particular, en el plano judicial ordinario, algunos órganos jurisdiccionales españoles han llegado a ejercer el control de convencionalidad con apoyo explícito en esa decisión de 23 de mayo de 2012 (Reclamación n. ${ }^{\circ}$ 65/2011) para, haciendo valer la prevalencia de un tratado (a la sazón, la Carta Social

recursos vinculadas al retroceso de las actividades, lo cual comportaría un atentado a las obligaciones de la Carta en materia de protección social». 
Europea) sobre la citada legislación de reforma del mercado laboral de 2012, descartar la aplicación de esta última: esa postura la inauguró la Sentencia n. ${ }^{\circ} 412 / 2013$, de 19 de noviembre de 2013, del Juzgado de lo Social n. ${ }^{\circ} 2$ de Barcelona (procedimiento n. ${ }^{\circ} 426 / 2013$ en materia de despido) y ha sido seguida con diversa intensidad por otros órganos jurisdiccionales del orden social. Lo curioso es que, incluso tras la Sentencia del Tribunal Constitucional núm. 119/2014, se ha seguido aplicando el criterio convencional marcado por el Comité Europeo en el ámbito de la jurisdicción ordinaria (por ejemplo, Sentencia n. ${ }^{\circ} 352$ de 5 de noviembre de 2014 del Juzgado de lo Social núm. 3 de Barcelona, procedimiento de despido n. ${ }^{\circ}$ 116/2014; ese criterio también ha sido seguido en apelación o suplicación por algunos Tribunales Superiores de Justicia ${ }^{6}$, sin que el Tribunal Supremo se haya pronunciado al respecto sobre el fondo) ${ }^{7}$, resaltando esas disposiciones constitucionales y el valor de la Convención de Viena de 1969 sobre el Derecho de los Tratados, una

6 Entre otros, por la Sala de lo Social del Tribunal Superior de Justicia de Canarias (por ejemplo, sentencias de fecha 28 de enero, 30 de marzo y 18 de abril de 2016, en los recursos de suplicación, respectivamente, núm. 581/2015, núm. 989/2015 y núm. 110/2016), o del Tribunal Superior de Justicia de Castilla y León (Valladolid; por ejemplo, sentencia de 26 de septiembre de 2015, recurso de suplicación núm. 1527/2016).

7 Efectivamente, el Auto de 4 de noviembre de 2015 de la Sala de lo Social del Tribunal Supremo resolvió declarar la inadmisión del recurso de casación para la unificación de doctrina interpuesto por un trabajador contra la sentencia dictada por la Sala de lo Social del Tribunal Superior de Justicia de Cataluña de fecha 2 de diciembre de 2014 (recurso de suplicación núm. 5253/14, interpuesto por la empresa condenada en la instancia) frente a la sentencia del Juzgado de lo Social núm. 1 de Mataró de fecha 9 de abril de 2014 (procedimiento de despido núm. 492/2013). Esta sentencia del Juzgado de lo Social había sido estimatoria y declaró que la extinción del contrato indefinido de apoyo a emprendedores del trabajador recurrente (este había empezado a prestar sus servicios el 14 de mayo de 2012, notificándole la empresa el 26 de abril de 2013 la extinción de su contrato con efectos de 13 de mayo de 2013, por no haber superado el período de prueba) debía ser calificada como despido improcedente. Lo interesante de la sentencia del Juzgado de lo Social es que, en una plausible argumentación jurídica que revela una correcta aprehensión del sistema constitucional de fuentes y particularmente del ordenamiento laboral, descarta la aplicación de la disposición (art. 4.3) de la Ley 3/2012, de 6 de julio, de reforma del mercado de trabajo, que estableció esa figura contractual, por disconformidad con el art. 4.4 de la Carta Social a la luz de la Decisión de fondo del Comité Europeo de Derechos Sociales de 23 de mayo de 2012 de resolución de la Reclamación núm. 65/2011 dictada contra Grecia. Con ello, el Juzgado de instancia ejerció con determinación y convicción el control de convencionalidad. 
internacionalización de nuestro ordenamiento constitucional que por lo demás ha sido consolidada y reforzada por la reciente Ley 25/2014, de 27 de noviembre, de Tratados y otros Acuerdos Internacionales.

Por añadidura, ese criterio de la jurisdicción ordinaria ejerciendo acertadamente el control de convencionalidad tampoco entra en colisión con el otro canon europeo (el de la Unión Europea), en la medida en que el Tribunal de Justicia de Luxemburgo ha decidido sencillamente eludir la problemática y declararse incompetente para enjuiciar el controvertido contrato de apoyo a emprendedores (Sentencia de 5 de febrero de 2015, Nisttahuz Poclava, asunto $\mathrm{C} 117 / 14)^{8}$. Por lo demás, incluso para quienes entendían (erróneamente) que las decisiones del Comité Europeo de Derechos Sociales de 2012 frente a Grecia no eran trasladables a España (por no haber aceptado nuestro país el procedimiento de reclamaciones colectivas), tampoco se reveló útil dicho pretexto tras la conclusión frente a España (en el marco del sistema de informes) en enero de 2015, en donde, precisamente con apoyo en la decisión sobre la Reclamación n. ${ }^{\circ}$ 65/2011 contra Grecia, declaró explícitamente que «el artículo 4, párrafo 3, de la Ley 3/2012 no es conforme al artículo 4.4 de la Carta de 1961».

En lo que concierne al segundo ámbito, a finales de diciembre de 2012 fueron adoptadas por el Comité Europeo cinco nuevas decisiones de fondo ( 7 de diciembre de 2012) de resolución de las reclamaciones (n. ${ }^{\circ} 76$ a 80/2012) que denunciaban las leyes anticrisis de 2010 adoptadas en Grecia imponiendo una reducción drástica de las pensiones tanto en el sector público como en el privado; todas ellas concluyeron que se había violado el art. 12 de la Carta Social (derecho a la seguridad social) 9 .

8 En dicha sentencia, el Tribunal de Luxemburgo se declaró incompetente para enjuiciar el controvertido contrato de apoyo a emprendedores (un año de período de prueba con posible despido sin preaviso ni indemnización) previsto por el art. 4.3 de la Ley española 3/2012, de 6 de julio, de reforma del mercado de trabajo. Una modalidad contractual análoga, introducida con anterioridad en Grecia asimismo por influencia de la Troika, que había sido declarada por el Comité Europeo contraria al art. 4.4 de la Carta Social Europea de 1961 (ratificada por España en 1980) mediante su Decisión de 24 de mayo de 2012 (Reclamación colectiva núm. 65/2011).

9 Reclamación núm. 76/2012, Federación de pensionistas asalariados de Grecia c. Grecia; reclamación núm. 77/2012, Federación Pan-helénica de pensionistas de la función pública c. Grecia; reclamación núm. 78/2012, Sindicato de pensionistas del personal ferroviario de Atenas-Piraeus c. Grecia; reclamación núm. 79/2012, Federación pan-helénica de pensionistas de la empresa pública de electricidad c. Grecia, y reclamación núm. 80/2012, Sindicato de pensionistas del Banco agrícola de Grecia c. Grecia. 
Es interesante traer a colación la fundamentación jurídica común de dichas decisiones:

1. ${ }^{\circ}$ El art. 12 de la Carta Social Europea está concebido más en términos de progresividad que de regresión. Pero, en caso de establecerse restricciones, ellas no deben conducir a una precarización o a una pauperización de la población afectada ${ }^{10}$.

2. El Gobierno griego no ha demostrado que, bajo el pretexto de las medidas de austeridad impuestas por la Troika, haya intentado adoptar otras medidas alternativas menos costosas para la población afectada.

3. ${ }^{\circ}$ Dicho Gobierno tampoco ha acreditado que haya habido consultas y diálogo con los interlocutores sociales en un ámbito tan esencial.

4. ${ }^{\circ}$ En fin, el efecto acumulativo de todos estos déficits, unido a las reducciones de las pensiones en sí, hace descansar exclusivamente sobre los pensionistas, en su calidad de contribuyentes, las consecuencias de la crisis económica de manera injustificada y contraria a la Carta Social Europea.

De nuevo, frente a ese canon europeo, la jurisdicción constitucional española ha adoptado decisiones divergentes, como ponen de manifiesto las sentencias núm. 49/2015, de 5 de marzo, y núm. 95/2015, de 14 de mayo, reveladoras de ese enfoque deficitario. En ellas se sustanciaron, respectivamente, un recurso de inconstitucionalidad ${ }^{11}$ y una cuestión de

10 ¿Cuál fue el alcance de esas reducciones o restricciones? Para el Comité Europeo de Derechos Sociales, si bien algunas primas o parte de las pagas extras (en Pascua, $\mathrm{Na}$ vidad y vacaciones) cabe reducirlas o incluso suprimirlas, las pensiones básicas y las complementarias no pueden reducirse de la manera tan drástica como se ha efectuado (en porcentaje de entre el $20 \%$ hasta el 50 \% según el montante de la pensión), pues ello no solo es contrario a esa obligación de los Estados de establecer progresivamente un régimen de seguridad social de un nivel más elevado (art. 12.3 de la Carta Social), sino que se aparta asimismo en muchos casos de situaciones vulnerables (las pensiones más bajas) de la obligación de protección social de las personas mayores (art. 4 del Protocolo de 1988), para que no queden por debajo del umbral mínimo de riesgo de pobreza, para lo que el Comité Europeo toma como referencia el $50 \%$ de la renta mediana ajustada que establece Eurostat en función de la riqueza y coyuntura económica de cada país.

11 Recurso de inconstitucionalidad núm. 1114-2013, interpuesto por más de 50 diputados integrantes de los grupos parlamentarios Socialista, Izquierda Unida, Iniciativa per Cataluña Verds-Esquerra Unida y Alternativa, Chunta Aragonesista, La Izquierda 
inconstitucionalidad ${ }^{12}$ frente al art. 2.1 del Real Decreto Ley 28/2012, de 30 de noviembre, de medidas de consolidación y garantía del Sistema de la Seguridad Social, mediante el que se dejaba sin efecto para el ejercicio 2012 la actualización de las pensiones prevista en la Ley de Clases Pasivas del Estado (Real Decreto Legislativo 670/1987, de 30 de abril) y en Ley General de Seguridad Social (Real Decreto Legislativo 1/1994, de 20 de junio). Los dos pronunciamientos constitucionales son desestimatorios y cuentan con opiniones discrepantes similares a las expresadas frente a la Sentencia núm. 119/2014. Y nuevamente, también en este terreno algunos órganos de la Jurisdicción Ordinaria, tanto Tribunal Superior de Justicia (Sala de lo Social) ${ }^{13}$ como Juzgado de lo Social ${ }^{14}$, han decidido ejercer el control de convencionalidad.

\section{CONTROL DE CONVENCIONALIDAD Y DERECHOS SOCIALES EN PERSPECTIVA COMPARADA LATINOEUROPEA}

\section{LA PRÁCTICAMENTE CONSOLIDADA EXPERIENCIA FRANCESA}

Ya se ha avanzado que el ordenamiento constitucional francés ha reconocido sin ambages en el art. 55 de su Constitución vigente de 1958 el carácter supralegal de los tratados y el control de convencionalidad. Concretamente, al acometer el alcance de dicha disposición constitucional, la doctrina gala ha constatado que «bajo la Va República, los tratados o convenios internacionales de entrada ostentan una posición privilegiada en la jerarquía de las normas jurídicas, por encima de la ley» (Formery, 2003: 108-109).

El caso es que las instancias jurisdiccionales supremas, de la justicia ordinaria primero, y de la justicia administrativa después, fueron consecuentes hace décadas derivando de dicha base constitucional el control de convencionalidad. En efecto,

Plural, Partido Nacionalista Vasco, Convergencia i Unió y Unión Progreso y Democracia.

12 Cuestión de inconstitucionalidad núm. 7434-2013, planteada por la Sala de lo Social del Tribunal Superior de Justicia del País Vasco.

13 Sentencia del Tribunal Superior de Justicia de Castilla-La Mancha (Sala de lo Social, Albacete) núm. 1040 de 6 de octubre de 2015 (recurso núm. 694/15), Fundamento Jurídico $3 .^{\circ}$.

14 Sentencia del Juzgado de lo Social núm. 12 de Barcelona núm. 287 de 4 de septiembre de 2015 (recurso núm. 220/2014), Fundamento Jurídico 4. ${ }^{\circ}$, en el que se alude expresamente a las Decisiones del Comité Europeo de Derechos Sociales de 7 de diciembre de 2012 sobre recorte de pensiones. 
al no estar habilitada ninguna jurisdicción, en el sistema francés, para censurar la ley, restaba por saber si las jurisdicciones administrativa y judicial se iban a mostrar dispuestas a aceptar la posibilidad de descartar su aplicación en el caso de haberse adoptado en contradicción con una norma internacional ya en vigor. La Corte de Casación tomó partido rápidamente en tal sentido (24 de mayo de 1975, Société des Cafés Jacques Vabre), haciendo prevalecer la norma internacional sobre la ley. Por el contrario, el Consejo de Estado, en nombre del respeto absoluto de la norma legislativa rehusó, hasta 1989, examinar la compatibilidad con un compromiso internacional de una ley posterior a dicho compromiso. Desde la Sentencia Nicolo (Consejo de Estado, 20 de octubre de 1989), un control efectivo de la norma establecida en el artículo 55 queda asegurado por los dos órdenes jurisdiccionales ordinarios. Pero se trata de un control por vía de excepción de la ley, que queda descartada puntualmente por el juez y no desaparece del ordenamiento jurídico (Formery, 2003: 110).

Pese a la experiencia del control de convencionalidad en el sistema constitucional francés (más consolidada que la más reciente del control de constitucionalidad difuso operado por los órganos jurisdiccionales), la actualidad de los derechos sociales ha revelado carencias en la justicia francesa a la hora de decantarse por el estándar más favorable del Consejo de Europa (de nuevo, la Carta Social y la jurisprudencia del Comité Europeo de Derechos Sociales) frente al más restrictivo de la Unión Europea (que ha ejercido una vis atractiva incoherente en este caso con el principio favor libertatis o pro personae). Resulta imperioso que la Carta Social Europea y las realizaciones del Comité dejen de estar «moderadamente infravaloradas» (Stangos, 2017: 3).

Sobre este punto, las estrategias procesales de órganos jurisdiccionales nacionales son determinantes en el momento de ejercer una voluntad positiva tendente a hacer valer el estándar más favorable. Lo ilustraré con un ejemplo crítico, que muestra que la justicia francesa (en este caso, la Corte de Casación) podía haber aplicado la solución más favorable ya sentada por el Comité Europeo de Derechos Sociales (ejerciendo su rica experiencia precedente sobre ejercicio directo del control de convencionalidad) en lugar de suscitar un control indirecto y diferido planteando una arriesgada e innecesaria cuestión prejudicial ante el Tribunal de Justicia de la Unión Europea que podía saldarse (como así sucedió) con una solución más restrictiva.

Ese riesgo se verificó con motivo de la Sentencia del Tribunal de Justicia de 15 de enero de 2014 (Association de médiation sociale, asunto C-176/2012), que trae su causa de la petición de decisión prejudicial formulada por la Corte de Casación francesa en el marco de un litigio entre la Association y diversos agentes sindicales acerca de la sujeción de la constitución de órganos representativos de personal a ciertos umbrales de trabajadores empleados; ello a la luz de la Directiva 2002/14/CE del Parlamento Europeo y del Consejo, de 11 de marzo de 2002, por la que se establece un marco general relativo a la 
información y a la consulta de los trabajadores en la Comunidad Europea, y del derecho fundamental a la información y consulta de los trabajadores en el seno de la empresa del art. 27 de la Carta de los Derechos Fundamentales.

Los avatares procesales nacionales vinieron precedidos de una controvertida prejudicialidad ante el Consejo Constitucional (una cuestión prioritaria de constitucionalidad que fue resuelta por este el 29 de abril de 2011 declarando que el art. L. 1111-3 del Código de trabajo era conforme con la Constitución francesa) ${ }^{15}$, cuya decisión no fue curiosamente acatada por el órgano jurisdiccional de primera instancia (el Tribunal de Instancia de Marsella, que decidió descartar la aplicación de ese canon constitucional dando primacía al derecho de la Unión Europea). Posteriormente, en vía casacional, la Corte de Casación gala formuló la cuestión prejudicial que dio origen a la Sentencia del Tribunal de Justicia de 15 de enero de 2014.

Esta venía sustancialmente a corroborar la posición del tribunal de instancia desautorizando el canon establecido por el Consejo Constitucional (apdo. 29) ${ }^{16}$, efectuando contrariamente a renglón seguido un salto cualitativo nada desdeñable al descartar no solo el efecto directo entre particulares de la Directiva 2002/14 (apdos. 30 a 41) ${ }^{17}$ sino, de manera más decepcionante aún, ese mismo efecto horizontal del art. 27 de la Carta de los Derechos Fundamentales (Lazzerini, 2014).

Con tal proceder, el Tribunal de Justicia no solo se apartaba de la razonable - y, a mi entender, acertada - lectura combinada de dicha directiva y del art. 27 de la Carta de los Derechos Fundamentales incluida en las conclusiones del

15 Así se recoge en los apdos. 17 y 18 de la Sentencia del Tribunal de Justicia de 15 de enero de 2014.

16 A tenor del apdo. 29 de la Sentencia del Tribunal de Justicia de 15 de enero de 2014 , «se ha de concluir que el artículo 3, apartado 1, de la Directiva 2002/14 debe interpretarse en el sentido de que se opone a una disposición nacional como el artículo L. 1111-3 del Código de trabajo, que excluye a los trabajadores titulares de contratos de trabajo apoyados del cómputo del personal de la empresa para la determinación del número de trabajadores requerido legalmente para constituir órganos de representación del personal».

17 El fallo de la Sentencia del Tribunal de Justicia de 15 de enero de 2014 dispone que el art. 27 de la Carta de los Derechos Fundamentales, "por sí solo o en conjunción» con la Directiva 2002/14/CE, «deben interpretarse en el sentido de que, cuando una disposición nacional de transposición de esa Directiva, como el artículo L. 1111-3 del Código de trabajo francés, es incompatible con el Derecho de la Unión, ese artículo de la Carta no puede ser invocado en un litigio entre particulares para excluir la aplicación de esa disposición nacional». 
abogado general Pedro Cruz Villalón ${ }^{18}$ —autorizada opinión saludada por la doctrina- (Millán Moro, 2014; Ward, 2014; Buffa, 2015; Laulom, 2014), sino, asimismo, del efecto útil del equivalente art. 21 de la Carta Social Europea revisada de $1996^{19}$. A este último respecto, en sus conclusiones publicadas en enero de 2015, el Comité Europeo condenó a Francia por los mismos motivos que los expresados en el apdo. 29 de la Sentencia del Tribunal de Justicia de la Unión Europea de 15 de enero de 2014, pero lógicamente por disconformidad del art. L. 1111-3 del Código de Trabajo con el citado art. 21 de la Carta Social ${ }^{20}$.

La lectura que, en mi opinión, se desprende de cuanto antecede es clara: primeramente, el Tribunal de Instancia de Marsella podría haber inaplicado el controvertido art. L. 1111-3 del Código laboral (previamente declarado conforme a la Carta Magna francesa por el Consejo Constitucional), no tanto acudiendo a los principios de primacía y efecto directo del derecho de la Unión Europea, sino ejerciendo el control de convencionalidad con apoyo en el art. 21 de la Carta Social; y, en segundo término, la propia Corte de Casación podría haber omitido el innecesario planteamiento de la cuestión prejudicial comunitaria, ejerciendo ese mismo control de convencionalidad para alcanzar la solución de aplicación horizontal de dicho art. 21 y evitando así el restrictivo fallo en tal sentido del Tribunal de Justicia.

En fin, semejante línea argumental se revela tanto más practicable en Francia cuanto que, como se viene reiterando, en el país vecino el control de convencionalidad se ha estado ejerciendo con naturalidad (Pacteau, 2004; De Lamy, 2009), ante la ausencia de la cuestión de inconstitucionalidad hasta hace pocos años (Bon, 2009: 321). Y, de hecho, tanto la Corte de Casación como instancias jurisdiccionales inferiores francesas cuentan ya con experiencia en materia de control de convencionalidad con apoyo en la Carta Social y en la jurisprudencia del Comité Europeo en ámbitos como las guardias localizadas/périodes d'astreinte o el sistema de remuneración a tanto alzado/forfait en jours (Johansson, 2013).

18 Apdos. 97 y 98 de las conclusiones de Pedro Cruz Villalón.

19 Véase asimismo el apdo. 52 de las conclusiones de Pedro Cruz Villalón.

20 Concluye el Comité: «La exclusión, establecida por el artículo L. 111-3 del Código, de los trabajadores titulares de contratos apoyados o tutelados del cálculo del efectivo de la empresa —cálculo necesario para la determinación de los umbrales mínimos que permiten la creación de instituciones representativas del personal que aseguren la información y la consulta de los trabajadores — no es conforme a la Carta [al art. 21 de la Carta Social Europea revisada]». 


\section{EL PESO ENTRECRUZADO DEL PARÁMETRO COMUNITARIO EUROPEO EN ITALIA}

En el sistema constitucional italiano, hasta hace pocos años anclado en el dualismo, el control de convencionalidad se ha analizado como temática más reciente asociada especialmente en un primer momento al papel de la justicia ordinaria con relación al Convenio Europeo de Derechos Humanos y al Tribunal Europeo de Derechos Humanos (Mirate, 2007). Ahora bien, como en el caso francés, en Italia ha ganado asimismo peso entrecruzado el parámetro comunitario europeo (Montanari, 2003: 143), con soluciones reacias hacia el ejercicio del control de convencionalidad y también más restrictivas para el disfrute efectivo de los derechos sociales.

Argumento a continuación esta crítica. En particular, hasta fechas recientes, incluso la Corte de Casación italiana utilizaba frases recurrentes con relación a la Carta Social Europea que evocaban esa postura reacia (Guiglia, 2013: 23) —en contraste con países como Francia, Bélgica u Holanda (Nivard, 2016)—, con expresiones del tipo «las disposiciones de la Carta no tienen eficacia directa en el ordenamiento interno de los Estados contrayentes, sino que se concretan en compromisos jurídicos de carácter internacional en las relaciones entre los mismos Estados, a quienes por ello mismo se les exige el cumplimiento de los principios y derechos en ella contemplados, con amplia discrecionalidad en cuanto a los modos, plazos y medios ${ }^{21}$ ». Sin embargo, ese carácter reacio es criticado en la doctrina italiana, que apunta cada vez más a una garantía integrada de los derechos humanos extraída de los varios niveles internacionales (Guiglia, 2014; Oliveri, 2007; Panzera, 2015).

Por su lado, volviendo al entrecruzamiento (rectius: interferencia) del parámetro comunitario europeo, es verdad que el propio Tribunal de Justicia de Luxemburgo no ha contribuido a potenciar el control de convencionalidad, al rechazar equipararlo a la primacía del derecho de la Unión Europea. Semejante postura viene ilustrada por la Sentencia del Tribunal de Justicia de Luxemburgo (Gran Sala) de 24 de abril de 2012 (caso Servet Kamberaj, asunto C-517/10), en la que se concluye:

La referencia que hace el artículo 6 del Tratado de la Unión Europea, apartado 3, al Convenio Europeo para la Protección de los Derechos Humanos y de las Libertades Fundamentales, hecho en Roma el 4 de noviembre de 1950, no obliga al juez nacional, en caso de conflicto entre una norma de Derecho nacional y dicho Convenio, a aplicar directamente las disposiciones del Convenio y a no aplicar la norma de Derecho nacional incompatible con el mismo.

21 Corte cass. civile, VI sez., 13 de julio de 2016, núm. 14340. 
El asunto no era menor en clave de diálogo entre jurisdicciones europeas y protección multinivel de derechos, pues versaba sobre la denegación de solicitud de vivienda a un residente europeo extracomunitario (albanés) de larga duración por agotamiento del presupuesto aprobado por la provincia autónoma de Bolzano para la concesión de dicha ayuda a los nacionales de países terceros. En la cuestión prejudicial formulada por el órgano jurisdiccional italiano se suscitó la posible sinergia entre los arts. 21 (no discriminación) y 34 (seguridad social y ayuda social) de la Carta de los Derechos Fundamentales de la Unión Europea y el principio de no discriminación reconocido por los artículos 14 del Convenio Europeo de Derechos Humanos y 1 del Protocolo n. ${ }^{\circ} 12$ al Convenio Europeo, sin que no obstante se trajera a colación el parámetro más específico e importante en este terreno como es el art. 31 de la Carta Social Europea revisada (derecho a la vivienda) y la jurisprudencia del Comité Europeo de Derechos Sociales en la materia ${ }^{22}$.

Resumiendo; tal como critiqué en el caso francés, la estrategia procesal de la justicia italiana podía haber consistido en aplicar directamente el parámetro más favorable de la Carta Social Europea ejerciendo el control de convencionalidad, en lugar de plantear esa innecesaria y arriesgada cuestión prejudicial ante el Tribunal de Justicia de la Unión Europea. Pues, finalmente, la postura del Tribunal de Justicia no se ha mostrado entusiasta con esa tutela multinivel de derechos recogida en el propio título VII de la Carta de los Derechos Fundamentales de la Unión Europea, ni tampoco muy coherente con las nociones de estándar mínimo y cláusula favor libertatis a que apuntan los arts. 52.3 y 53 de esa Carta Europea de Derechos.

\section{LA INFLUENCIA CONDICIONANTE DEL CONTROL DE CONSTITUCIONALIDAD EN PORTUGAL}

En el ordenamiento y doctrina portugueses no parece arraigada la temática del control de convencionalidad, tal vez por el amplio alcance de su sistema de control de constitucionalidad (Duarte y Gomes, 2008: 259), que se ha mostrado asimismo bastante incisivo en materia de derechos sociales, incluso en el contexto de la crisis económica (como se concreta a continuación). Por tal razón, al haberse explotado con carácter evolutivo los cánones de producción interna ante el propio Tribunal Constitucional portugués depurando la

22 De hecho, en las explicaciones del Praesidium anexas a la Carta de los Derechos Fundamentales se dice explícitamente, con respecto a su art. 34, que «el apartado 3 se inspira en el artículo 13 de la Carta Social Europea y en los artículos 30 y 31 de la Carta Social revisada». 
legislación interna que hubiera podido plantear asimismo potenciales dudas de contrariedad con los parámetros internacionales sobre derechos sociales, el control de convencionalidad por la justicia ordinaria ha quedado relegado a un plano secundario; ello al margen de una ulterior supervisión constitucional del eventual ejercicio del control convencionalidad (Duarte y Gomes, 2008: 264).

Sentado lo anterior, reviste interés aludir a dos sentencias del Tribunal Constitucional portugués cuya jurisprudencia presenta bastantes analogías con la establecida por el Comité Europeo de Derechos Sociales en sus ya citadas cinco decisiones de 7 de diciembre de 2012 sobre el sistema griego de pensiones (reclamaciones n. ${ }^{\circ} 76$ a 80/2012).

La primera sentencia portuguesa es la Decisión n. ${ }^{\circ} 353$ de 3 de julio de 2012, cuyo objeto de controversia fueron diversas disposiciones de la ley de presupuestos para 2012 mediante las que se suspendía entre 2012 y 2014 el abono de las pagas extraordinarias que normalmente se hacen efectivas en Navidad y meses de vacaciones con respecto a sueldos públicos y pensionistas, justificando el legislador dichas medidas en aras del respeto de los límites de déficit presupuestario (4,5\% del PIB en 2012) impulsados por los memorandos de la Troika. La Corte Constitucional lusa declaró inconstitucionales algunas de esas medidas sobre la base de una argumentación conjunta con apoyo en los principios de seguridad jurídica, proporcionalidad e igualdad, por cuanto debían limitarse los sacrificios impuestos a las mismas categorías de personas en comparación con otras no afectadas por dichas medidas, dado que esa diferencia de trato resultaba desproporcionada.

La segunda resolución portuguesa guarda directa conexión con la anterior, pues tiene su origen precisamente en la declaración de inconstitucionalidad precedente, tras la cual el legislador intentó adoptar nuevas medidas que conciliaran el doble objetivo de luchar contra el déficit y de evitar una nueva censura por parte del Tribunal Constitucional. Se trata de la Decisión n. ${ }^{\circ} 187$ de 5 de abril de 2013, mediante la que se censuraron nuevamente los recortes de salarios a los funcionarios públicos y de las pensiones de jubilación por violación del principio de igualdad (al no ponderarse debidamente la justa distribución de las cargas públicas) y por vulneración del principio de proporcionalidad como consecuencia de los efectos acumulativos y continuos de los sacrificios impuestos a los trabajadores del sector público y a los pensionistas. Igual que sucedió con las decisiones del Comité Europeo de Derechos Sociales, sumamente complejas en cuanto a su examen, se ha apuntado que la Decisión n. ${ }^{\circ} 187$ de 2013 del Tribunal Constitucional portugués es una de las resoluciones "más difíciles de la jurisprudencia de crisis», no solo por la extensión de los motivos impugnatorios, sino también por «la complejidad 
de las cuestiones constitucionales suscitadas» (Baylos Grau, 2013: 26; Guerra Martins, 2016: 45; Guillem Carrau, 2013: 69).

Como apunte de crítica constructiva cabe concluir que la reseñada jurisprudencia constitucional portuguesa sobre derechos sociales, pese a su carácter avanzado en cuanto al resultado, hubiera podido enriquecerse y reforzarse en sus bases argumentativas acudiendo a los estándares europeos específicos sobre derechos sociales, especialmente la Decisión n. ${ }^{\circ} 187$ de 2013 (por tanto, posterior a las decisiones del Comité Europeo sobre Grecia). En efecto, esa omisión de los concretos parámetros internacionales sobre derechos sociales, al margen de la referencia siempre absorbente del Convenio Europeo de Derechos Humanos (en dicha Decisión n. ${ }^{\circ} 187$ de $2013)^{23}$, resulta tanto menos comprensible cuanto que, como bien se ha recordado, «las principales fuentes del capítulo de la Constitución relativo a los derechos sociales son la Carta Social Europea de 1961 y el Pacto Internacional de Derechos Económicos, Sociales y Culturales de la ONU de 1966. La mayor parte de las disposiciones de la Constitución sobre los derechos económicos, sociales y culturales son transcripciones literales de esas dos convenciones internacionales» (Moreira, 2016: 35).

\section{REFLEXIONES FINALES: LA INCOMPRENSIBLE DESAFECCIÓN ACADEMICISTA Y LA POSITIVA VOLUNTAD JURISDICCIONAL EN EL EJERCICIO DEL CONTROL DE CONVENCIONALIDAD Y EL RESPETO DE LA DIGNIDAD}

Llegados a este punto, comprobamos que los derechos sociales dotan de una nueva dimensión al control de convencionalidad en el continente europeo. En este, los diversos operadores jurídicos se encuentran menos familiarizados, y acaso se muestran más reticentes que en el continente americano, a la hora de explotar positivamente ese instituto, dinamizador de la justicia ordinaria como pieza clave del sistema institucional, como elemento articulador del sistema de fuentes y como eje vertebrador del sistema de derechos

23 Concretamente, en cuanto a la toma en consideración de los parámetros europeos, únicamente en el apdo. 61 de ese Acórdão 187/2013 de 5 de abril de 2013 (Tribunal Constitucional, Plenário, Processo No. 2/2013, 5/2013, 8/2013 e 11/2013; https:// bit.ly/2T7W8xR) se incluye una genérica referencia al art. 1 del Protocolo núm. 1 al Convenio Europeo para afirmar simplemente que el Tribunal Europeo de Estrasburgo ha analizado con apoyo en dicha disposición situaciones en las que estaban en juego las pensiones. 
humanos en pro del respeto de la dignidad. A tal efecto, deben aunarse los esfuerzos de la academia y de la Judicatura.

Con tales premisas, de la experiencia comparada latinoeuropea analizada en el presente trabajo se desprenden algunas cuestiones críticas que deben propiciar una mejora de la puesta en práctica del control de convencionalidad. A semejante optimización contribuye que la novedosa jurisprudencia del Comité Europeo de Derechos Sociales esté terciando en el debate, académico y judicial.

Así, en el caso de España, los derechos sociales y el parámetro jurisprudencial de la instancia de garantía de la Carta Social Europea han hecho aflorar una atención nada desdeñable con respecto al control de convencionalidad, de manera más ostensible en la doctrina laboralista y en los órganos jurisdiccionales ordinarios del orden social (Salcedo Beltrán, 2016a: 27), lo cual ha generado a su vez una discusión al respecto en el seno del Tribunal Constitucional; la mayoría de magistrados constitucionales, hasta la fecha, no solo no se ha mostrado receptiva a esa jurisprudencia europea (en contraste con la minoría discrepante), sino que se ha apartado deliberadamente de ella en el terreno de las medidas de austeridad «anticrisis» impulsadas desde la Unión Europea.

Al contrario, las sentencias estudiadas del Tribunal Constitucional de Portugal han convergido con el criterio jurisprudencial del Comité Europeo de Derechos Sociales. Ahora bien, con relación a esas decisiones portuguesas de «jurisprudencia de crisis», cabe criticar que no se hagan eco explícitamente de esa jurisprudencia más específica del Comité Europeo (especialmente en el supuesto de la Decisión n. ${ }^{\circ} 187$ de 2013, que es posterior a las decisiones del Comité Europeo sobre el sistema griego de pensiones), puesto que, aunque resulte suficiente la filiación normativa constitucional, la base jurídica europea es susceptible de aportar un plus de legitimidad interpretativa, al sugerir un estándar continental compartido y abierto a la tutela multinivel (Valdés Dal-Ré, 2016a: 110). En cuanto a la Decisión n. ${ }^{\circ} 353$ de 2012, es cierto que se podría haber planteado ante el Comité Europeo a través del procedimiento de reclamaciones colectivas (pues no es preciso agotar los recursos previos, a diferencia del procedimiento de demanda individual ante el Tribunal Europeo de Estrasburgo) en lugar de acudir al Tribunal Constitucional portugués, si bien la sentencia de este ha sido — como se avanzaba — convergente con la decisión del Comité Europeo de Derechos Sociales. No obstante, esa opción de los recurrentes de residenciar el caso ante la Jurisdicción Constitucional portuguesa en lugar de someterlo al Comité Europeo presentaba riesgos potenciales de divergencia si la sentencia constitucional hubiese sido desestimatoria y entonces una ulterior decisión europea hubiere acogido la reclamación. 
En el caso de Italia, ha sido criticada la ausencia de voluntad jurisdiccional como falta de "sensibilidad de la judicatura» al subrayar el paralelismo entre el principio de primacía del derecho de la Unión Europea y el carácter supralegal del Convenio Europeo de Derechos Humanos (Montanari, 2003: 142); una asimetría en perjuicio del canon del Consejo de Europa que todavía ha sido más acentuada en el ámbito de los derechos sociales. Si bien, recientemente, se ha acrecentado el interés de la doctrina italiana por la jurisprudencia del Comité Europeo de Derechos Sociales, sin duda merced a la adopción de relevantes decisiones de este con relación a Italia en el marco del procedimiento de reclamaciones colectivas.

En fin, en el caso de Francia, el clásico y asentado control de convencionalidad, incluso con relación a la Carta Social Europea y a la jurisprudencia del Comité Europeo, no ha conseguido eludir la interferencia menos favorable de la jurisprudencia del Tribunal de Justicia de la Unión Europea. Ello se ha debido en buena medida al planteamiento innecesario de cuestiones prejudiciales ante la Justicia comunitaria europea, en supuestos en donde el ejercicio del control de convencionalidad aplicando directamente el estándar del Consejo de Europea hubiera evitado un pronunciamiento restrictivo o elusivo de la Corte de Luxemburgo (por ejemplo, en la citada Sentencia de 15 de enero de 2014, Association de médiation sociale, asunto C-176/2012). Semejante estrategia jurisdiccional, potencial y realmente generadora de divergencias interpretativas ha sido lamentablemente practicada asimismo en España (verbigracia, la Sentencia del Tribunal de Justicia de 5 de febrero de 2015, Nisttahuz Poclava, asunto C117/14).

En estas condiciones, en caso de divergencias jurisprudenciales, la opción de la jurisdicción nacional — que cobra una especial relevancia en la supervisión de la Carta Social Europea (García Blasco y Álvarez Gimeno, 2017: 984) - por la solución más favorable al ejercicio de los derechos fundamentales (con eventual ejercicio del control de convencionalidad en caso de que la legislación nacional aparezca alineada con la solución más restrictiva) habrá de verificarse mientras persistan dichas asimetrías. Por otra parte, si esos contenciosos paralelos entre instancias supranacionales hacen emerger una voluntad jurisdiccional positiva de enriquecimiento mutuo (convergencias) por parte del órgano que había generado una jurisprudencia más restrictiva, esa adaptación no constituirá en absoluto un signo de debilidad, sino, muy al contrario, un gesto de vigoroso dinamismo y positiva mutua influencia; o sea, un loable escenario de diálogo judicial global y de aproximación sistemática (Ferrer Mac-Gregor y Herrera García, 2013).

En última instancia, tan loable reto culminará exitosamente solo si la doctrina y la judicatura, junto con los demás operadores jurídicos, se implican decididamente haciendo valer una positiva voluntad académica y jurisdiccional. 


\section{Bibliografía}

Aparicio Pérez, M. A. (1989). La cláusula interpretativa del artículo 10.2 de la Constitución española, como cláusula de integración y apertura constitucional a los derechos fundamentales. Jueces para la Democracia, 6, 9-18.

Bandrés Sánchez-Cruzat, J. M. (1996). Derecho Administrativo y Tribunal Europeo de Derechos Humanos. Madrid: Civitas; Ministerio de Justicia.

Baylos Grau, A. (2013). La contracción del Estado social. Revista de Derecho Social, 63, 11-34.

Bazán, V. (2010). Corte Interamericana de Derechos Humanos y Cortes Supremas o Tribunales Constitucionales Latinoamericanos: el control de convencionalidad y la necesidad de un diálogo interjurisdiccional crítico. Revista Europea de Derechos Fundamentales, 16, 15-44.

Bidart Campos, G. J. (1994). La interpretación del sistema de derechos humanos. Revista del Instituto Interamericano de Derechos Humanos, 19, 11-46.

— (1996). El Derecho constitucional humanitario. Buenos Aires: Ediar.

Bon, P. (2009). La cuestión prejudicial de constitucionalidad en Francia: ¡solución o problema? Teoría y Realidad Constitucional, 23, 313-325. Disponible en: https://doi.org/10.5944/trc.23.2009.6849.

Bonet Pérez, J. (2016a). Introducción general: presupuestos y dinamismo evolutivo de la exigibilidad jurídica internacional de los derechos económicos, sociales y culturales. En J. Bonet Pérez y R. A. Alija Fernández (eds.). La exigibilidad de los derechos económicos, sociales y culturales en la Sociedad internacional del siglo XXI: una aproximación jurídica desde el Derecho internacional. Madrid: Marcial Pons. (2016b). Reflexiones sobre la aplicabilidad en España de las opiniones y decisiones de los órganos de expertos internacionales especializados en derechos económicos, sociales y culturales. En J. Bonet Pérez y R. A. Alija Fernández. El control de los Tratados Internacionales de Derechos Humanos: realidad y limites. Una aproximación a la labor de los órganos de expertos desde la perspectiva de la efectividad de los derechos económicos, sociales y culturales. Barcelona: Atelier.

Buffa, F. (2015). I licenziamenti nel Jobs Act e nelle norme internazionali. Milano: Key Editore.

Cançado Trindade, A. A. (1995). Reflexiones sobre la interacción entre el Derecho internacional y el Derecho interno en la protección de los derechos humanos. Procurador de los derechos humanos.

Canosa Usera, R. (2015). El control de convencionalidad. Madrid: Civitas; Thomson Reuters.

Carcassonne, G. (2002). La Constitution. Paris: Éditions du Seuil.

De Carreras Serra, F. (2000). Función y alcance del artículo 10.2 de la Constitución. Revista Española de Derecho Constitucional, 60, 321-341.

De Lamy, B. (2009). Chronique de droit pénal international. Revue de science criminelle et de droit pénal comparé, 1, 154-172. 
Duarte, M. L. y Amado Gomes, C. (2008). Portugal. En J. Tajadura Tejada y J. De Miguel Bárcena (coords.). Justicia Constitucional y Unión Europea. Madrid: Centro de Estudios Políticos y Constitucionales.

Fernández de Casadevante y Romaní, C. y Jiménez García, F. (2006). El Derecho Internacional de los Derechos Humanos en la Constitución Española: 25 Años de Jurisprudencia Constitucional. Madrid: Thomson; Civitas.

Ferrer Mac-Gregor, E. y Herrera García, A. (coords.) (2013). Diálogo Jurisprudencial en Derechos Humanos. Entre Tribunales Constituciones y Cortes Internacionales. Valencia: Tirant lo Blanch.

Formery, S. L. (2003). La Constitution commentée article par article. Paris: Hachette.

García Blasco, J. y Álvarez Gimeno, R. (2017). Supervisión y reclamaciones: especial referencia al Comité Europeo de Derechos Sociales. Artículo C y Protocolo de 1991, y artículo D y Protocolo de 1995. En C. Monereo Atienza y J. L. Monereo Pérez (dirs. y coords.). La garantía multinivel de los derechos fundamentales en el Consejo de Europa. El Convenio Europeo de Derechos Humanos y la Carta Social Europea. Granada: Comares.

Gelli, M. A. (2007). El liderazgo institucional de la Corte Suprema y las perplejidades del caso Mazzeo. La Ley, 71 (236).

Guerra Martins, A. M. (2016). La jurisprudence constitutionnelle portugaise sur la crise de la dette publique, vue par une ancienne juge à la Cour. Semaine sociale Lamy, 1746, 35-44.

Guiglia, G. (2013). La rilevanza della Carta sociale europea nell'ordinamento italiano: la prospettiva giurisprudenziale. Disponible en: http://www.federalismi.it, 18.

- (2014). The importance of the European Social Charter in the Italian Legal System: in pursuit of a stronger protection of social rights in a normative and internationally integrated system. En M. D'Amico y G. Guiglia (eds.). European Social Charter and the challenges of the XXI century. La Charte Sociale Européenne et les défis du XXI $I^{E}$ siècle. Napoli: Edizioni Scientifiche Italiane.

Guillem Carrau, J. (2013). El Constitucional Portugués ante las medidas de ajuste: la Sentencia de 5 de abril de 2013. Cuadernos Manuel Giménez Abad, 5, 69-77.

Hitters, J. C. (2009). Control de constitucionalidad y control de convencionalidad. Comparación (criterios fijados por la Corte Interamericana de Derechos Humanos). Estudios Constitucionales, 2, 109-128. Disponible en: https://doi. org/10.4067/S0718-52002009000200005.

Jimena Quesada, L. (2013). Jurisdicción nacional y control de convencionalidad. Cizur Menor: Aranzadi.

- (2016). Social Rights and Policies in the European Union: New Challenges in a Context of Economic Crisis. Valencia: Tirant lo Blanch.

Jiménez García, F. (2015). La protección internacional de los derechos sociales y económicos. Avances recientes, técnicas de aplicación y propuestas de reforma constitucional. Revista Europea de Derechos Fundamentales, 25, 29-59. 
Johansson, A. (2013). Influence sur le droit français de la directive temps de travail 2003/88 (anc. 93/104) et la jurisprudence de la Cour de Justice y afférente (hors congés payés). Droit Social, 9, 821.

Laulom, S. (2014). Les seuils d'effectif: une confirmation et une déception. Semaine Sociale Lamy, 1640.

Lazzerini, N. (2014). Causa C-176/12. Association de médiation sociale: la Corte di giustizia rompe (...in parte) il silenzio sugli effetti orizzontali della Carta. Diritti comparati. Comparare i diritti fondamentali in Europa. Disponible en: https://bit.ly/2Q0NCyp.

Millán Moro, L. (2014). Sentencia del Tribunal de Justicia de 15.1.2014 (Gran Sala), Association de Médiation Sociale, Asunto C-176/12. Eficacia directa versus primacía. Revista de Derecho Comunitario Europeo, 49, 1029-1045.

Mirate, S. (2007). Giustizia amministrativa e convenzione europea dei diritti dell'uomo. L'altro diritto europeo in Italia, Francia e Inghilterra. Napoli: Jovene.

Molina Navarrete, C. (2014). Reforma laboral y "Justicia Constitucional»: el Tribunal Constitucional ni es «infalible» ni ya tiene la «última palabra». Comentario a la STC 129/2014, de 16 de julio, RI 5603-2012, interpuesto por el Parlamento de Navarra contra la Ley 3/2012, de 6 de julio, de reforma del mercado de trabajo. Revista de Trabajo y Seguridad Social-Centro de Estudios Financieros, 377-378, 183-190.

Montanari, L. (2003). Giudici comuni e Corti sovranazionali: rapporti tra sistemi. En P. Falzea, A. Spadaro, y L. Ventura (eds.). La Corte Costituzionale e le Corti d'Europa: Atti del seminario (Copanello, 31 maggio-1 giugno 2002). Torino: Giappichelli.

Moreira, V. (2016). Droits sociaux constitutionnels sous pression: lessons de l'expérience portugaise. Semaine sociale Lamy, 1746.

Nivard, C. (2016). L'effet direct de la Charte sociale européenne devant le juge administratif. Retour sur la question évolutive de l'effet direct des sources internationales. Revue des Droits et Libertés Fondamentaux, 22. Disponible en: https:// bit.ly/2PyvRtm.

Oliveri, F. (2007). La lunga marcia verso l'effettività. La Carta sociale europea tra enunciazione dei diritti, meccanismi di controllo e applicazione nelle corti nazionali. Disponible en: https://bit.ly/2RmkoKY.

Panzera, C. (2015). La "voce” del Comitato europeo dei diritti social. En B. Caruso y G. Fontana (coords.). Lavoro e diritti sociali nella crisi europea. Un confronto fra costituzionalisti e giuslavoristi. Bologna: Il Mulino.

Pacteau, B. (2004). Relazione sulla Francia. En AA. VV. Atti del Convegno Principi giuridici e limiti all'autonomia dei legislatori. Profili internazionali, supranazionali e nazionali. Napoli: Università di Napoli l'Orientale.

Peces-Barba Martínez, G. (1988). La elaboración de la Constitución de 1978. Madrid: Centro de Estudios Constitucionales.

Riofrío Martínez-Villalba, J. C. (2007). ¿Prevalecen los tratados internacionales sobre la Constitución? Propuesta de una doctrina no extremista. Anuario de Derecho Constitucional Latinoamericano, 2007 (1), 259-281 
Rouvillois, F. (2002). Droit constitutionnel. Fondements et pratiques. Paris: Flammarion.

Sagüés, N. P. (2011). El «control de convencionalidad» en el sistema interamericano y sus anticipos en el ámbito de los derechos económico-sociales. Concordancias y diferencias con el sistema europeo. En A. Von Bogdandy, H. Fix-Fierro, M. Morales Antoniazzi, E. Ferrer Mac-Gregor (coords.). Construcción y papel de los derechos sociales fundamentales. Hacia un Ius Constitutionale Commune en América Latina (pp. 381-417). México, DF: UNAM; Instituto de Investigaciones Jurídicas.

Sáiz Arnáiz, A. (1999). La apertura constitucional al Derecho internacional y europeo de los derechos humanos. El articulo 10.2 de la Constitución española. Madrid: Consejo General del Poder Judicial.

Salcedo Beltrán, C. (2016a). La aplicabilidad directa de la Carta Social Europea por los órganos judiciales. Trabajo y Derecho: Nueva Revista de Actualidad y Relaciones Laborales, 13, 27-52.

— (2016b). La réforme du marché du travail en Espagne. Semaine Sociale Lamy, 1746.

Santiago Rivera, C. A. (2016). La duración del período de prueba en la Jurisprudencia Constitucional Española. Revista de Administración Pública, 47, 309-364.

Stangos, P. (2017). Avant-propos. En P. Stangos y C. Deliyanni-Dimitrakou (eds.). Parcours en Europe sociale, à bord du Comité européen des droits sociaux/Journeys in Social Europe, on board of the European Committee of Social Rights. Atenas; Tesalónica: Sakkoulas Publications.

Tajadura Tejada, J. y De Miguel Bárcena, J. (coords.) (2008). Justicia Constitucionaly Unión Europea. Madrid: Centro de Estudios Políticos y Constitucionales.

Torres del Moral, A. (2010). El Tribunal Constitucional español en negativo: lagunas y rectificaciones; cuestiones disputadas, inéditas, irresueltas, menores y de lege ferenda. En V. Bazán (coord.). Derecho Procesal Constitucional Americano y Europeo. Tomo I. Buenos Aires: Abeledo Perrot.

Valdés Dal-Ré, F. (2016a). El constitucionalismo laboral europeo y la protección multinivel de los derechos laborales fundamentales: luces y sombras. Albacete: Bomarzo. (2016b). La protection des droits sociaux en Espagne. Semaine Sociale Lamy, 1746.

Ward, A. (2014). Art. 51. Scope. En S. Peers, T. Hervey, J. Kenner, A. Ward (eds.). The EU Charter of Fundamental Rights. A Commentary. Oxford: Hart Publishing. 